\title{
In-service shear check of heated cased insulated flowlines
}

\author{
Zhao Tianfeng ${ }^{1 *}$, Duan Menglan ${ }^{1}, \mathrm{Jia} \mathrm{Xu}^{2}$ and Jiao Bintian ${ }^{2}$ \\ ${ }^{1}$ Offshore Oil/Gas Research Center, China University of Petroleum, Beijing 102249, China \\ ${ }^{2}$ CNOOC Research Institute, Beijing 100027, China
}

(C) China University of Petroleum (Beijing) and Springer-Verlag Berlin Heidelberg 2012

\begin{abstract}
Starting friction would be induced and preserved somewhere along the seabed route of cased insulated flowlines (CIF) when the pipe carries service loads. The axial pipe-soil interaction can be divided into three pipe sections: the sliding section, the fixed section and the starting friction section. Although limited to a relatively small length of the pipe, the pipe coats of the starting friction section would suffer much higher shear force caused by thermal expansion than those of the sliding section or the fixed section. Based on the axial equilibrium equation of this kind of insulated pipeline, we developed a method for checking the shear force on CIF coats and their interfaces. The typical example shows that starting friction effect should be taken into account when checking the lap shear strength of heatshrinkable sleeves on CIF field joints.
\end{abstract}

Key words: Cased insulated flowlines, starting friction, thermal expansion, shear failure

\section{Introduction}

The cased insulated flowline (CIF) is composed of the carrier pipe, insulated coat, protective coat and the concrete weighted coat. CIF is more economical for high-temperature transportation than steel pipe-in-pipe systems if some engineering handicaps can be effectively overcome (Morris et al, 1979; Guidetti et al, 1996). For most cases the CIF is laid on the seabed directly or in a trench without embedment, and shear forces will be induced in the pipe coats or at interfaces of those coats due to thermal expansion (Palle and Ror, 1998). For shear check in practice, the most uncertain factor still is seabed-pipe interaction, which has been discussed intensively, for example the works of Reese and Casbarian (1968), Wagner et al (1987), Dendani and Jaeck (2007), Oliphant and Maconochie (2007), Rong et al (2009) and those from JIP projects (Bruton et al , 2008; Carr et al, 2008).

Internal pressure and high temperature of service makes the CIF tend to expand and induce the axial friction between the seabed and the outermost concrete coat. The SAFEBUCK JIP project has presented research on heated pipelines expanding on the seabed when pipe-soil interaction mainly includes the 'breakout' and 'residual' axial friction. So the JIP approach provided an axial friction model expressed by $F_{\mathrm{A}}=W \cdot \zeta \cdot \mu_{\mathrm{a}}$, in which $W$ is the submerged weight of the pipe, $\mu_{\mathrm{a}}$ is the axial friction coefficient, and $\zeta$ is the wedging factor. In this definition the product $W \cdot \zeta$ represents the effective contact force including the 'wedging' effect, which provides

*Corresponding author. email: zhaotianfeng@sina.com

Received October 10,2011 a horizontal component of the contact force between the pipe and the soil (raising the total normal force between the pipe and the seabed to exceed the weight alone).

Based on the axial pipe-soil interaction, the seabed routing of CIF can be divided into three sections, which respectively are the sliding section, the fixed section and the starting friction section. As there is no movement tendency in the axial direction, the fixed section does not preserve seabed friction, but beyond the fixed section when the local pipe section tends to slide the starting friction force would firstly be triggered and once the pipeline moves sliding friction is preserved. So the pipeline route beyond the fixed section can be further divided into the sliding section and the starting friction section. For the heated CIF the axial compressive force on the wall of the innermost carrier pipe would not be entirely released because of friction constraints applied to the outermost concrete coat, but partial release of the axial force may induce axial shear forces in the CIF coats and their interfaces for axial movement of the carrier pipe. At the same time in the pipeline routing for those CIF simple roots where mobilization friction triggered on their concrete coats more remarkable shear forces would be induced on their inner pipe coats and coat interfaces. To check the shear forces on the CIF coats or coat interfaces, the axial starting friction needs to be first investigated well, but it is difficult to develop a distribution function of starting friction by analyzing the interaction of the pipeline and seabed. Furthermore the finiteelement (FE) algorithms based on resolving the displacements of freedom degrees of element nodes also cannot be used to describe such a starting friction action which hardly drives movement. For these reasons available literature on thermal 
expansion analysis has not involved shear checks of starting friction sections of this kind of pipelines.

Combining the axial interaction characteristics of submarine pipelines and the seabed, this paper develops an integrated shear check approach for cased insulated flowlines in service.

\section{Thermal expansion equilibrium of CIF on the seabed}

In service the axial force on the wall of carrier pipes drives the sliding section of the CIF moving towards pipeline terminals, at this time the sum of seabed axial friction on the sliding section and the sum of shear force in any one of the pipe coats of the sliding section are both equal to the axial force drop in the carrier pipe of the sliding section. From the fixed section to the pipeline terminal the drop in the axial force on the carrier pipe is approximately equal to the total seabed friction force induced outside the weighted coat, including the sliding friction and the starting friction, which is shown in Fig. 1.

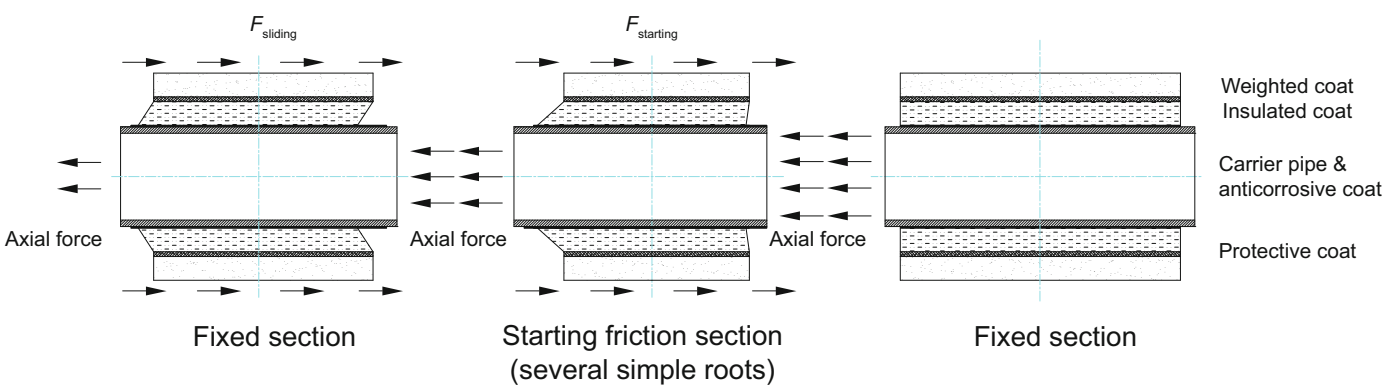

Fig. 1 Axial force drop in the carrier pipe of the cased insulated flowline

(The concrete weighted coat is discontinuous)

In the starting friction section of the cased insulated flowline, the axial force drop in the carrier pipe and the starting friction effect of the seabed has the following relationship:

$$
\left.\frac{\mathrm{d} f}{\mathrm{~d} x}\right|_{x=L_{0}}=w \cdot \zeta \cdot \mu_{\mathrm{a} \max }
$$

where $f(x)$ is the axial force on the carrier pipe of the CIF route, $\mathrm{kN} ; L_{0}$ is the position coordinate of the breakout point of axial starting friction, $\mathrm{m} ; w$ is the submerged weight of the pipeline per unit length, $\mathrm{kN} / \mathrm{m}$; and $\mu_{\text {amax }}$ is the maximum starting friction coefficient of pipe/soil interaction which is dimensionless.

Furthermore, at the junction position of the starting friction section and the fixed section, the gradient of the axial force on the carrier pipe is zero, which is shown in Fig. 2.

$$
\left.\frac{\mathrm{d} f}{\mathrm{~d} x}\right|_{x=L_{\text {sliding }}+L_{\text {starting }}}=0
$$

where $L_{\text {sliding }}$ is the length of the sliding section, m; and $L_{\text {starting }}$ is the length of the starting section, $\mathrm{m}$.

For CIF systems, only the innermost carrier pipe is continuous and all the other coats are discontinuous, so the axial balance of the carrier pipe has the following relationship:

$$
L_{\text {sliding }} \cdot W \cdot \zeta \cdot \mu_{\text {asliding }}+\int_{L_{\text {sliding }}}^{L_{\text {sliding }}+L_{\text {starting }}} F_{\mathrm{A}}^{\prime}(x) \mathrm{d} x=f_{0}-f_{\text {spool }}
$$

were $F_{\mathrm{A}}{ }^{\prime}(x)$ is the the density distribution function along the starting friction section; and $\mu_{\text {asliding }}$ is the residual friction coefficient of the sliding pipe section in the axial direction.

In Eq. (3), $f_{0}$ is the axial force on the fixed section of the carrier pipe, which can be calculated as:

$$
f_{0}=E \cdot A \cdot \alpha \cdot\left(T-T_{0}\right)+A \cdot\left(\frac{P r_{\mathrm{c}}}{2 t}-v \frac{P r_{\mathrm{c}}}{t}\right)
$$

where $E, A, v$ and $\alpha$ are Young's modulus (MPa), cross- sectional area $\left(\mathrm{mm}^{2}\right)$, Poisson's ratio and the coefficient of linear thermal expansion of the carbon steel of carrier pipes $\left({ }^{\circ} \mathrm{C}^{-1}\right) ; r_{\mathrm{c}}$ and $t$ are the carrier pipe radius and the wall thickness respectively, $\mathrm{mm}$; and $T$ is the CIF service temperature, ${ }^{\circ} \mathrm{C} ; T_{0}$ is its installation temperature, ${ }^{\circ} \mathrm{C} ; P$ is the service pressure difference of the $\mathrm{CIF}, \mathrm{MPa}$.

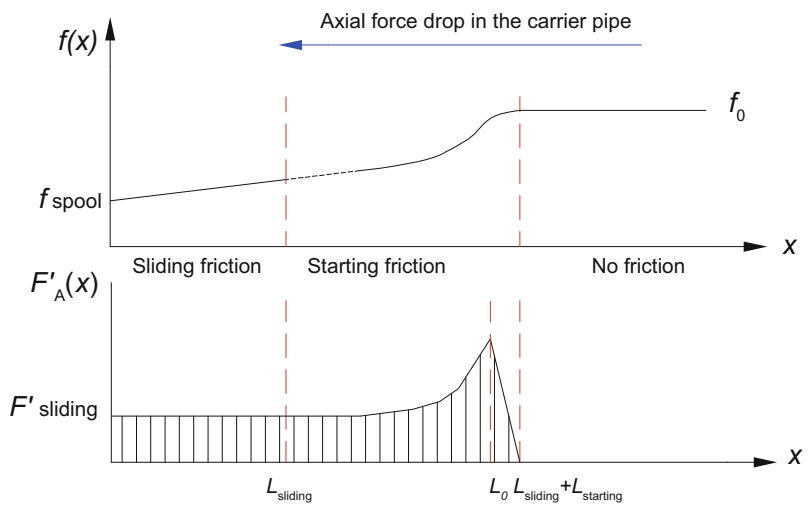

Fig. 2 Axial force $(f(x))$ and density distribution function $\left(F_{\mathrm{A}}^{\prime}(x)\right)$ of the cased insulated flowline

Also in Eq. (3), $f_{\text {spool }}$ is the reaction force of the terminal spool and can be given by:

$$
f_{\text {spool }}=\gamma_{\text {spool }} \cdot K_{\text {spool }}
$$

where $K_{\text {spool }}$ and $\gamma_{\text {spool }}$ is the bending stiffness and the angular deformation of the terminal spool in the CIF system.

Then substituting Eqs. (4) and (5) into Eq. (3) yields:

$$
\begin{aligned}
& L_{\text {sliding }} \cdot W \cdot \mu_{\text {asliding }}+\int_{L_{\text {sliding }}}^{L_{\text {siding }}+L_{\text {sarting }}} F_{\mathrm{A}}^{\prime}(x) \mathrm{d} x \\
& =E \cdot A \cdot \alpha \cdot\left(T-T_{0}\right)+A \cdot\left(\frac{P r_{\mathrm{c}}}{2 t}-v \frac{P r_{\mathrm{c}}}{t}\right)-\gamma_{\text {spool }} \cdot K_{\text {spool }}
\end{aligned}
$$

Eq. (6) can serve as the axial equilibrium equation of the CIF, in which the length $L_{\text {sliding }}$ and $L_{\text {starting }}$, the friction density 
distribution function $F_{\mathrm{A}}{ }^{\prime}(x)$, and the angular deformation of the terminal spool $\gamma_{\text {spool }}$ are unknown.

The terminal elongation of the carrier pipe of the heated CIF can be expressed as:

$$
\begin{aligned}
& \Delta=d_{\text {offset }} \cdot \gamma_{\text {spool }} \\
& =\int_{0}^{L_{\text {sliding }}} \varepsilon_{\text {sliding }}(x) \mathrm{d} x+\int_{L_{\text {sliding }}}^{L_{\text {siding }}+L_{\text {starting }}} \varepsilon_{\text {starting }}(x) \mathrm{d} x
\end{aligned}
$$

where $d_{\text {offset }}$ is the offset distance of the terminal spool; $\varepsilon_{\text {sliding }}(x)$ and $\varepsilon_{\text {starting }}(x)$ are the axial strain function of the sliding section and the starting friction section, respectively. In practice the value of the last term of Eq. (7) is small and can be ignored, so Eq. (7) can be simplified as:

$$
\Delta=d_{\text {offset }} \cdot \gamma_{\text {spool }}=\int_{0}^{L_{\text {siding }}} \varepsilon_{\text {sliding }}(x) \mathrm{d} x
$$

For the sliding section of the carrier pipe, the axial strain can be expressed:

$$
\varepsilon_{\text {sliding }}(x)=\varepsilon_{\mathrm{T}, \mathrm{P}}+\varepsilon_{\text {spool }}+\varepsilon_{\mathrm{f}}(x)
$$

where $\varepsilon_{\mathrm{T}, \mathrm{P}}$ is the axial thermal expansion strain and pressuredifferential strain of the carrier pipe; $\varepsilon_{\text {spool }}$ is the axial strain induced by the terminal spool force; $\varepsilon_{\mathrm{f}}(x)$ is the axial strain induced by the accumulated friction force, and

$$
\begin{aligned}
& \varepsilon_{\mathrm{T}, \mathrm{P}}=\alpha \cdot\left(T-T_{0}\right)+\frac{1}{E} \cdot\left(\frac{P r_{\mathrm{c}}}{2 t}-v \frac{P r_{\mathrm{c}}}{t}\right) \\
& \varepsilon_{\text {spool }}=-\frac{K_{\text {spool }} \gamma_{\text {spool }}}{E A} \\
& \varepsilon_{\mathrm{f}}(x)=-\frac{\mu_{\text {asliding }} \cdot W \cdot \zeta \cdot x}{E A}
\end{aligned}
$$

So substituting the three above equations into Eq. (8) yields the following formula to calculate the terminal elongation of the insulated flowline in service.

$$
\begin{aligned}
& \Delta=d_{\text {offset }} \cdot \gamma_{\text {spool }}=\int_{0}^{L_{\text {sliding }}}\left[\varepsilon_{\mathrm{T}, \mathrm{P}}+\varepsilon_{\text {spool }}+\varepsilon_{\mathrm{f}}(x)\right] \mathrm{d} x \\
& =\left[\alpha \cdot\left(T-T_{0}\right)+\frac{1}{E} \cdot\left(\frac{P r_{\mathrm{c}}}{2 t}-v \frac{P r_{\mathrm{c}}}{t}\right)\right] \cdot L_{\text {sliding }} \\
& -\frac{K_{\text {spool }} \gamma_{\text {spool }}}{E A} \cdot L_{\text {sliding }}-\frac{\mu_{\text {asliding }} \cdot W \cdot \zeta}{2 E A} \cdot L_{\text {sliding }}^{2}
\end{aligned}
$$

\section{Shear force check of the heated insulated flowline}

The starting friction section is the most probable location where shear failure may occur in the CIF system. To check the shear strength of pipe coats or coat interfaces, the total starting friction on a half of the pipeline can be expressed as:

$$
\begin{aligned}
& \int_{L_{\text {sliding }}}^{L_{\text {sliding }}+L_{\text {starting }}} F_{\mathrm{A}}^{\prime}(x) \mathrm{d} x \\
& =\int_{L_{\text {sliding }}}^{L_{0}} F_{\mathrm{A}}^{\prime}(x) \mathrm{d} x+\int_{L_{0}}^{L_{\text {sliding }}+L_{\text {starting }}} F_{\mathrm{A}}^{\prime}(x) \mathrm{d} x
\end{aligned}
$$

We know the starting displacement is very small and the second term at the right side of Eq. (14) can be ignored at engineering precision. So approximately there is:

$$
\int_{L_{\text {sididing }}}^{L_{\text {siding }}+L_{\text {starting }}} F_{\mathrm{A}}^{\prime}(x) \mathrm{d} x \approx \int_{L_{\text {sliding }}}^{L_{0}} F_{\mathrm{A}}^{\prime}(x) \mathrm{d} x
$$

Another acceptable assumption can be proposed that the action length of the starting friction is confined to several simple roots of the CIF system and the axial density distribution function on the concrete weighted coat of these simple roots can be expressed as:

$$
F_{\mathrm{A}}^{\prime}(\xi)=F_{\mathrm{V}}^{\prime} \cdot \mu_{\mathrm{a}}(\xi)=\int_{\operatorname{arc}} g_{\mathrm{V}}(z, \theta) \mathrm{d} s \cdot \mu_{\mathrm{a}}(\xi)
$$

where $F_{\mathrm{V}}{ }^{\prime}(\theta)$ is the vertical contact force per unit length, $\mathrm{kN} / \mathrm{m}$; $\theta$ is the angle coordinate of the pipe cross section and $\xi$ is the axial coordinate of this pipe section.

The normal contact force on the unburied pipeline $F_{\mathrm{V}}{ }^{\prime}(\theta)$ is the sum of the vertical component of tangential stress and that of the normal stress on the pipe-soil contact surface. On this contact surface of the weighted coat and the subsea soil, based on the limit equilibrium and limit analysis, the tangential stress and the normal stress can respectively be expressed as:

$$
\begin{aligned}
& \tau_{n}=c \cdot \sin 2 \delta \\
& \sigma_{n}=\gamma z+c \cdot(1+\cos 2 \delta+2 \delta+\pi-2 \theta)
\end{aligned}
$$

where $\delta$ is the angle of friction and $c$ is the undrained strength of subsea soil (Shi and Yan, 2003). $g_{\mathrm{V}}(z, \theta)$ can be expressed as:

$$
g_{\mathrm{V}}(z, \theta)=\sigma_{n} \cos \theta+\tau_{n} \cdot \sin \theta
$$

For $H<D / 2$ (as shown in Fig. 3), $\alpha=\cos ^{-1}(1-2 H / D)$; for $H>D / 2, \alpha=\pi-\cos ^{-1}(2 H / D-1)$, here $H$ is the pipe penetration and $D$ is the external diameter of the weighted coat. Position variables $\theta$ and $z$ in Eq. (19) satisfies $z=D \cdot(\cos \theta-\cos \alpha) / 2$, so by Eqs. (17), (18) and (19), $F_{\mathrm{A}}^{\prime}(x)$ in Eq. (15) can be expressed as a function of coordinates $\theta$ and $\xi$. Fig. 3 provides a schematic diagram of the CIF pipe partly sinking into the soft clay seabed (Westgate et al, 2010).

For submarine pipelines with an external diameter of $0.2-$ $1.0 \mathrm{~m}$, resting on clays with an undrained shear strength of $0.8-70 \mathrm{kPa}$, the formula proposed by Verley and Lund (1995) is suitable to calculate the penetration, that is

$$
\frac{H}{D}=0.0071\left(S \cdot G^{0.3}\right)^{3.2}+0.062\left(S \cdot G^{0.3}\right)^{0.7}
$$

with

$$
\begin{aligned}
& S=w /\left(D \cdot S_{\mathrm{u}}\right) \\
& G=S_{\mathrm{u}} /(D \cdot \gamma)
\end{aligned}
$$

where $S_{\mathrm{u}}$ is the undrained shear strength, $\mathrm{kPa} ; \gamma$ is the submerged soil density, $\mathrm{kN} / \mathrm{m}^{3}$; and $H$ is the submerged 


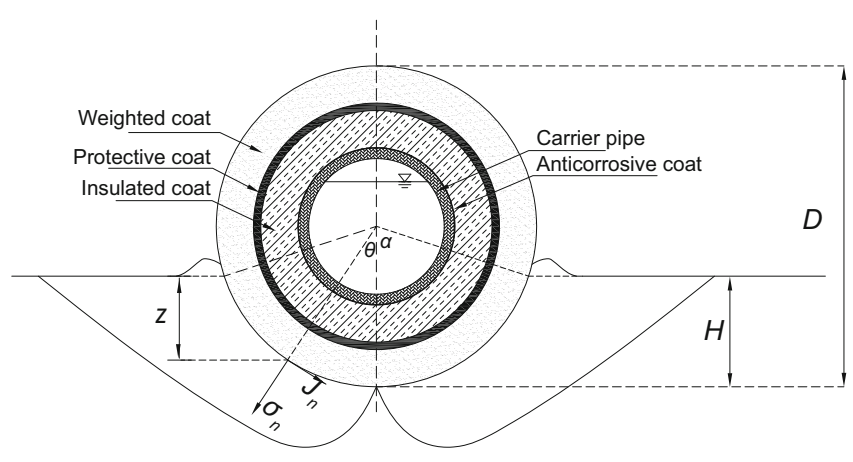

Fig. 3 The CIF pipe embedded into the soft clay seabed

weight of the CIF system.

The dotted line in Fig. 4 is one group of axial friction response data provided in the JIP project. At the beginning of the axial movement of the pipe, a high frictional coefficient $(0.45)$ appears which can be seen as the starting friction response, and the steep downward segment is the static friction dissipating and the final stable frictional coefficient $(0.17)$ belongs to the residual friction.

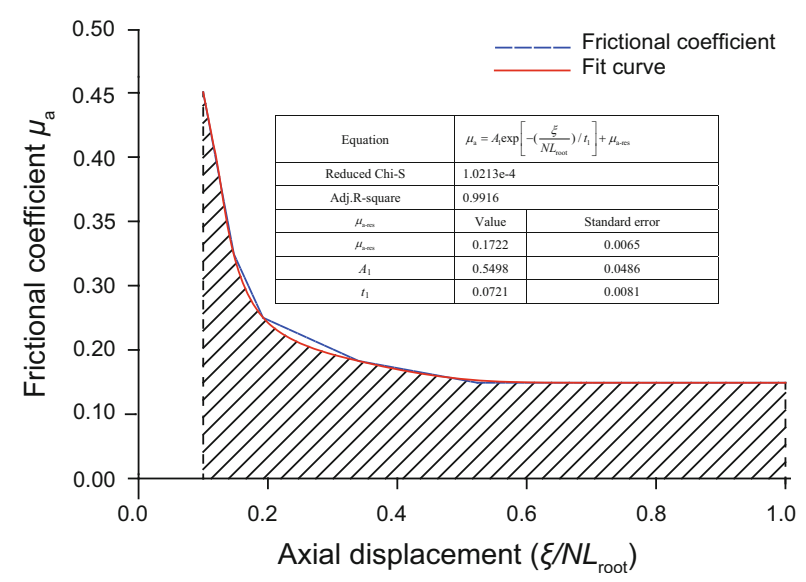

Fig. 4 Fitting of friction coefficient (here $\xi$ is the local axial coordinate)
The first order exponential decay function is selected to fit this friction response data and when the length of starting friction section is $N L_{\text {root }}$ an axial frictional coefficient expression can be given as:

$$
\mu_{\mathrm{a}}\left(\frac{\xi}{N \cdot L_{\text {root }}}\right)=0.1722+0.5498 \mathrm{e}^{-\left(\frac{\xi}{N \cdot L_{\text {root }}}\right) / 0.0721}
$$

Moreover, the total shear force on these simple roots can be calculated as:

$$
\begin{aligned}
& Q=\int F_{\mathrm{V}}^{\prime} \mu_{\mathrm{a}}(\xi) \mathrm{d} \xi=\int_{\mathrm{arc}} g_{\mathrm{V}}(z, \theta) \mathrm{d} s \cdot \int_{0}^{N \cdot L_{\text {root }}} \mu_{\mathrm{a}}(\xi) \mathrm{d} \xi \\
& =\int_{-\alpha}^{\alpha} \frac{D}{2} \cdot g_{\mathrm{V}}(z, \theta) \mathrm{d} \theta \cdot \int_{0}^{N \cdot L_{\text {root }}} \mu_{\mathrm{a}}(\xi) \mathrm{d} \xi
\end{aligned}
$$

For a typical CIF system with design parameters in Table 1 (Cao et al, 2005), when the axial friction response approaches to that of Fig. 4, a shear check can be given based on the shear force calculated from Eq. (22).

By Eq. (20) the penetration of the CIF system (Table 1) in the seabed is $119 \mathrm{~mm}$, less than $D / 2$, and $\alpha=\cos ^{-1}(1-2 z / D)=71.9^{\circ}$. If the starting friction responses among ten simple roots of the CIF systems, that is $N \cdot L_{\text {root }}=121.92 \mathrm{~m}$, the integration result of Eq. (22) is 39.1 $\mathrm{kN}$, which was a result from effective contact force and had included the 'wedging' effect of pipe-soil interaction.

Therefore, the average shear stress on the insulated coat or that on the interface of the carrier pipe and the insulated coat is $39.1 \mathrm{kN} /\left(\pi \cdot D C_{\text {O.D. }} \times 10\left(L_{\text {root }}-L_{\mathrm{FJ}}\right)\right)=0.639 \mathrm{kPa}$, and the maximum shear stress of those positions is twice of the average shear stress, and reaches $1.277 \mathrm{kPa}$. So for a usual bearing condition of seabed, the thermal shear stress on the CIF coats and their interfaces is far less than the shear allowable values which are listed in Table 1. However the field joints of the CIF system are weak positions and according to the lap shear strength of the heat-shrinkable sleeve $\left(12\right.$ psi (i.e. $82.8 \mathrm{kPa}$ ) at $120{ }^{\circ} \mathrm{C}$ ) this shear load is remarkable and needs an sleeve overlap area of $472 \mathrm{~cm}^{2}$ at

\begin{tabular}{|c|c|c|c|c|c|}
\hline & Materials & Dimensions & Properties & Materal shear strengths & Interface shear strengths \\
\hline Carrier pipe & Steel (API 5L X65) & $\begin{array}{c}D C_{\text {O.D. }}=168.3 \mathrm{~mm} \\
T C_{\mathrm{W} . \mathrm{T} .}=11.1 \mathrm{~mm}\end{array}$ & $E=207000 \mathrm{MPa}, v=0.3$ & $448 \times 0.6=268.8 \mathrm{MPa}$ & \multirow{4}{*}{$\begin{array}{c}0.112 \mathrm{MPa} \text { between the } \\
\text { insulated coat and the } \\
\text { protective coat }\end{array}$} \\
\hline Anticorrosive coat & Epoxy powder & $T_{\text {A.C. }}=0.4 \mathrm{~mm}$ & - & - & \\
\hline Insulated coat & Polyurethane & $T_{\mathrm{I} . \mathrm{C} .}=40 \mathrm{~mm}$ & $E=2.17 \mathrm{MPa}, \rho=60 \mathrm{~kg} / \mathrm{m}^{3}$ & $0.19 \mathrm{MPa}$ & \\
\hline Protective coat & Polyethylene & $T_{\mathrm{P.C} .}=8 \mathrm{~mm}$ & $E=490-700 \mathrm{MPa}, \rho=940 \mathrm{~kg} / \mathrm{m}^{3}$ & $0.26 \mathrm{MPa}$ & \\
\hline Weighted coat & Concrete & $T_{\mathrm{W.C} .}=40 \mathrm{~mm}$ & $E=26480 \mathrm{MPa}, \rho=2480 \mathrm{~kg} / \mathrm{m}^{3}$ & $40 \mathrm{MPa}$ & \multirow{4}{*}{$\begin{array}{l}0.2 \mathrm{MPa} \text { between } \\
\text { the protective coat } \\
\text { and the weighted coat }\end{array}$} \\
\hline Field joint coat & Heat-shrinkable sleeve & $\begin{array}{l}\text { Corrosic } \\
\text { for polyp }\end{array}$ & $\begin{array}{l}\text { prevention and sealing } \\
\text { pylene coated pipelines }\end{array}$ & $\begin{array}{l}\text { Peel strength } 8.28 \mathrm{e}-2 \mathrm{MPa} \\
\text { at } 120^{\circ} \mathrm{C}(\mathrm{ASTM} \mathrm{D}-1002)\end{array}$ & \\
\hline Submerged weight & $w=698.85 \mathrm{~N} / \mathrm{m}$ & \multicolumn{2}{|c|}{ Interface friction angle $\delta=20^{\circ}$} & $L_{\text {root }}=12.2 \mathrm{~m}$ & \\
\hline Undrained strength & $c=0.6 \mathrm{kPa}$ & \multicolumn{2}{|c|}{ Submerged soil density } & $\gamma=2.9 \mathrm{kN} / \mathrm{m}^{3}$ & \\
\hline
\end{tabular}
least.

Table 1 Typical parameters of a cased insulated flowline

\section{Conclusions}

1) Starting friction of axial pipe-soil interaction may cause much high shear force on the multi-coating system of the insulated flowline and shear checks of CIF coats and their interfaces, especially the shear check of the CIF field joint, should take seabed starting friction into account.

2) By the limit equilibrium and limit analysis, the normal 
contact force between the CIF system and the seabed soil can be determined and a first order exponential decay function can be used to fit the starting friction coefficient along the CIF route.

3) If the friction distributions can be acquired by an experiment or a reliable field test, the elongation of CIF system and the angular deformation of the CIF terminal spool due to thermal expansion can be calculated with the axial thermal expansion equilibrium equation.

4) The pipe section with severe axial out-of-straightness would trigger more frictional resistance during thermal expansion than an ideal straight pipeline, so the corresponding shear check should include this effect conservatively in practice.

5) Repeated thermal loads due to switch operations may cause complex soil reactions (DNV-2000) and at this time the shear forces induced in CIF coats or coat interfaces need to be further discussed.

\section{References}

Bruton D A S, White, D J, Carr M et al. Pipe-soil interaction during lateral buckling and pipeline walking: The SAFEBUCK JIP. Offshore Technology Conference, 5-8 May 2008, Houston, Texas, USA (OTC 19589)

Cao J, Wang Z L, Yan S W, et al. Inter-surface shear stress analysis for sub-sea pipelines with insulation foam. China Offshore Oil and Gas (Engineering). 2005. 17(2): 128-131 (in Chinese)

Carr M, Sinclair F and Bruton D. Pipeline walking: Understanding the field layout challenges, and analytical solutions developed for the SAFEBUCK JIP. SPE Projects, Facilities \& Construction. 2008. 3(3): $1-9$

Dendani $\mathrm{H}$ and Jaeck C. Pipe-soil interaction in highly plastic clays Proceedings of the 6th International Offshore Site Investigation and Geotechnics Conference: Confronting New Challenges and Sharing Knowledge, 11-13 September 2007, London, UK

Guidetti G P, Rigosi G L and Marzola R. The use of polypropylene in pipeline coatings. Progress in Organic Coatings. 1996. 27(1-4):7985 (Proceedings of the 20th International Conference in Organic Coatings Science and Technology)

Morris W W, Kaplan K B and Muhs S H. New technology in insulated offshore pipelines-design and installation. Offshore Technology Conference, 30 April-3 May 1979, Houston, Texas, USA (OTC 3476)

Oliphant $\mathrm{J}$ and Maconochie A. The axial resistance of buried and unburied pipelines. Proceedings of the 6th International Offshore Site Investigation and Geotechnics Conference: Confronting New Challenges and Sharing Knowledge, 11-13 September 2007, London, UK

Palle S and Ror L. Thermal insulation of flowlines with polyurethane foam. Offshore Technology Conference, 4-7 May 1998, Houston, Texas, USA (OTC8783)

Reese L C and Casbarian A O P. Pipe soil interaction for a buried offshore pipeline. Fall Meeting of the Society of Petroleum Engineers of AIME, 29 September-2 October 1968, Houston, Texas, USA (paper SPE 2343)

Rong H, Inglis R, Bell G, et al. Evaluation and Mitigation of axial walking with a focus on deep water flowlines. Offshore Technology Conference, 4-7 May 2009, Houston, Texas, USA (OTC 19862)

Shi H W and Yan S W. Settlement calculation of shore pipeline. China Offshore Oil and Gas (Engineering). 2003. 15(2): 1-5 (in Chinese)

Veritas D N. Submarine Pipeline Systems. Offshore Standard OS-F101, DNV-2000

Verley R and Lund K M. A soil resistance model for pipelines placed on clay soils. Proceedings of the 14th International Conference on Offshore Mechanics and Arctic Engineering, 18-22 June 1995, Copenhagen, Denmark. Vol. 5: 225-232

Wagner A D, Muff J D, Brennodden H, et al. Pipe-soil interaction model. Proceeding of the 19th Offshore Technology Conference, 27-30 April 1987, Houston, Texas

Westgate Z J, White D J, Randolph M F and Brunning P. Pipeline laying and embedment in soft fine-grained soils: Field observations and numerical simulations. Offshore Technology Conference, 3-6 May 2010, Houston, Texas, USA (OTC 20407)

(Edited by Sun Yanhua) 